\title{
Indoor Air Pollution by Tobacco Smoke and Study on Tobacco Use Among School and College Students in India
}

\author{
Jyotsna Lal \\ Department of Chemistry,Christ Church P.G College . Kanpur. U.P. 208001 \\ *Corresponding Author: jyotsna_lal@yahoo.com
}

\begin{abstract}
Copyright (C) 2013 Horizon Research Publishing All rights reserved.
\end{abstract}
\begin{abstract}
Burning tobacco is the main source of indoor pollution in the developed world. Tobacco smoke contains about 4,000 chemicals including carcinogens, irritants and toxic gases. The health impact of breathing environmental tobacco smoke is well documented. Tobacco smoke contains over 4000 chemicals in the form of particles and gases.Many potentially toxic gases are present in higher concentrations in sidestream smoke than in mainstream smoke and nearly $85 \%$ of the smoke in a room results from sidestream smoke. The particulate phase includes tar (itself composed of many chemicals), nicotine, benzene and benzo(a)pyrene. The gas phase includes carbon monoxide, ammonia, dimethylnitrosamine, formaldehyde, hydrogen cyanide and acrolein. Some of these have marked irritant properties and some 60 are known or suspected carcinogens (cancer causing substances). The Environmental Protection Agency (EPA) in the USA has classified environmental tobacco smoke as a class A (known human) carcinogen along with asbestos, arsenic, benzene and radon gas.[WHO 2004] Breathing other people's smoke is called passive, involuntary or secondhand smoking. The non-smoker breathes "sidestream" smoke from the burning tip of the cigarette and "mainstream" smoke that has been inhaled and then exhaled by the smoker. Secondhand smoke (SHS) is a major source of indoor air pollution. In the longer term, passive smokers suffer an increased risk of a range of smoking-related diseases.Non-smokers who are exposed to passive smoking in the home, have a 25 per cent increased risk of heart disease and lung cancer.This paper deals with study of various effects of passive smoking on human health as well as how adolescent school and college students are most influenced by tobacco use around them and get initiated easily in smoking .
\end{abstract}

Keywords Indoor Pollution, Adolescent, Secondhand Smoke, Lethal Doses, Carcinogen, Role Models

\section{Introduction}

Burning tobacco is the main source of indoor pollution in the developed world. Tobacco smoke contains about 4,000 chemicals including carcinogens, irritants and toxic gases. The health impact of breathing environmental tobacco smoke is well documented. Tobacco smoke contains over 4000 chemicals in the form of particles and gases.Many potentially toxic gases are present in higher concentrations in sidestream smoke than in mainstream smoke and nearly $85 \%$ of the smoke in a room results from sidestream smoke. The particulate phase includes tar (itself composed of many chemicals), nicotine, benzene and benzo(a)pyrene. The gas phase includes carbon monoxide, ammonia, dimethylnitrosamine, formaldehyde, hydrogen cyanide and acrolein. Some of these have marked irritant properties and some 60 are known or suspected carcinogens (cancer causing substances). The Environmental Protection Agency (EPA) in the USA has classified environmental tobacco smoke as a class A (known human) carcinogen along with asbestos, arsenic, benzene and radon gas.[1,13,14,17-22] Adolescents and children are the prime targets of the tobacco industry when recruiting new smokers. About 20 million children of ages 10-14 are estimated to be tobacco-addicted according to a survey done by the National Sample Survey Organization of the Indian Government. To this astounding figure, about 5500 new users are added every day, making two million new users every year. Adolescents typically become addicted to nicotine while still being teenagers In table 1 [A and $\mathrm{B}$ ], the standards indoor air quality levels for various public places are given. In table 2 , the minimum lethal doses for nicotine for mammals are given. In table 3 the various role models' ever seen smoking cigarette by students are given.The smokers are generally family, teacher ,popular film stars or celebrity. While in table 4 Health risk behaviours concerning tobacco use among adolescents are given who have tried smoking to eventually become smokers. In table 5 . Data of studies on tobacco use among school and college students are given.In_table 6. Studies on tobacco use among medical students in India. [3],[2 ]

According to the most recent Government of India's National Sample Survey data, there are 184 million tobacco consumers in India. About $40 \%$ of them use smokeless tobacco, $20 \%$ consume cigarettes, and another $40 \%$ smoke beedis.Smokeless tobacco use includes pan masala and 
chewing of tobacco in different forms.Tobacco is also smoked using indigenous devices like hooka, chhutta or dhumti in different parts of the country. Thus, in contrast to the other parts of the world, tobacco is used in a variety of ways in India, which include smoking and smokeless tobacco use. [4,5]Indian pipe) is an indigenous device,made out of wooden and metallic pipes, used for smoking tobacco.The tobacco smoke passes through water kept in a spherical receptacle,in which some aromatic substances may also be added. Hooka smoking is a common method of socializing among the village folk, especially in the Northern and Eastern parts of India, and is a part of the rural cultural life. Its use is more common among the adults and older generation. However, it is not popular among adolescents, because the adults generally discourage younger population from using hooka.Hookli is a short clay pipe-like device, being about $7 \mathrm{~cm}$ long, and is used for smoking tobacco in some parts of the country.Chhutta is a coarsely prepared roll of tobacco (cheroot), smoked with the burning end inside the mouth (reverse chhutta smoking). Its use is prevalent in coastal areas of the province of Andhra Pradesh in southeastern India. Dhumti is a cigar-like product made by rolling tobacco leaves inside the leaf of jackfruit tree. Occasionally, dried leaf of a banana plant is used. Males smoke dhumti in conventional manner, whereas females smoke it in a reverse manner, i.e.,keeping the burning end inside the mouth. Dhumti smoking is quite popular in the Goa province of the Western India.Chillum is a conical clay-pipe of about $10 \mathrm{~cm}$ long. The narrow end is put inside the mouth, often wrapped in a wet cloth that acts as a filter. This is used to smoke tobacco alone or tobacco mixed with ganja (marijuana) in northern parts of the country.[5]

Table 1. Indoor Air Pollution Factors

\begin{tabular}{|c|c|}
\hline A]. Indoor Air Pollution Levels Of Nicotine \\
\hline & Nicotine $\mu \mathrm{g} / \mathrm{m}^{3}$ \\
\hline Billiard parlour & 19.4 \\
\hline Home & $12.1-14.4$ \\
\hline Departmental store & 0.6 \\
\hline Automobile & 0.4 \\
\hline
\end{tabular}

Table 1[B]. Indoor Air Quality - Permitted Toxic Levels Of Nicotine In Public Places.

\begin{tabular}{|c|c|c|}
\hline & Nicotine $\mu \mathrm{g} / \mathrm{m}^{3}$ & Average $\mu \mathrm{g} / \mathrm{m}^{3}$ \\
\hline \multirow{2}{*}{ Offices } & $0.5-37$ & 5.4 \\
\cline { 2 - 3 } & $7.1-37$ & 15 \\
\cline { 2 - 3 } & $9-32$ & 5 \\
\hline Public common areas & $6-20$ & \\
\cline { 2 - 3 } & $2-36$ & 15 \\
\hline $\begin{array}{c}\text { Smoking sections of } \\
\text { airplanes }\end{array}$ & $1-3$ & 9 \\
\cline { 2 - 3 } & $0-29$ & 6 \\
\hline $\begin{array}{c}\text { Non smoking sections of } \\
\text { airplanes }\end{array}$ & $0-412$ & 2.3 \\
\hline $\begin{array}{c}\text { Food counters of } \\
\text { shopping malls }\end{array}$ & $1.6-3.1$ & \\
\hline
\end{tabular}

Table 2. Toxic Levels Of Nicotine Intake For Various Mammals

\begin{tabular}{|c|c|}
\hline \multicolumn{2}{|c|}{ A] Minimum Lethal Dose of Nicotine for mammals } \\
\hline Human & $0.36 \mathrm{mg} / \mathrm{kg}$ \\
\hline Adult Human & $\begin{array}{c}40 \mathrm{mg} \sim 0.5-1.0 \mathrm{mg} / \mathrm{kg} \text {; Topically } \\
\text { Child } 4 \mathrm{mg} / \mathrm{kg} \text {, Adult } 65 \mathrm{mg}\end{array}$ \\
\hline $\begin{array}{c}\text { Cow [1- } 1 \frac{1 / 2}{2} \text { year old Bulls \& } \\
\text { Heifer }]\end{array}$ & $>1 \mathrm{gm}$ \\
\hline Horse \& Cow & $200-400 \mathrm{mg}$ \\
\hline Sheep & $100-200 \mathrm{mg}$ \\
\hline 18 month Lambs & $200-300 \mathrm{mg}$ \\
\hline Cat \& Dog & $20-100 \mathrm{mg}$ \\
\hline Mouse & $40 \mathrm{mg}$ \\
\hline \multicolumn{2}{|c|}{ B] Toxic Levels of Nicotine intake for human baby } \\
\hline Mothers Smoking & 20 cigarettes \\
\hline Babies receive & $9.3 \mu \mathrm{g} / \mathrm{kg} /$ day Nicotine \\
\hline Breast milk & $200-500 \mathrm{ppb}$ \\
\hline
\end{tabular}

Table 3A. Demographic profile of study population.

\begin{tabular}{|c|c|c|}
\hline & $\begin{array}{l}\text { Number of } \\
\text { Respondents }\end{array}$ & $\begin{array}{l}\text { Exposure to Household } \\
\text { ETS }\end{array}$ \\
\hline \multicolumn{3}{|l|}{ Gender } \\
\hline Men & 25926 & $9965(37.0 \%)$ \\
\hline Women & 35183 & $18307(52.0 \%)$ \\
\hline \multicolumn{3}{|l|}{ Age } \\
\hline $15-24$ years & 19811 & $9771(49.3 \%)$ \\
\hline 25-34 years & 15670 & $7730(49.3 \%)$ \\
\hline $35-44$ years & 10998 & $4904(44.6 \%)$ \\
\hline $45-54$ years & 7558 & $2934(38.8 \%)$ \\
\hline 55-64 years & 4437 & $1663(37.5 \%)$ \\
\hline $65-74$ years & 2572 & $919(35.7 \%)$ \\
\hline$>=75$ years & 1063 & $351(33.0 \%)$ \\
\hline \multicolumn{3}{|c|}{ Usual residence } \\
\hline Rural & 27032 & $16140(59.7 \%)$ \\
\hline Urban & 33806 & $11408(33.7 \%)$ \\
\hline Mixed & 1271 & $724(57.0 \%)$ \\
\hline \multicolumn{3}{|c|}{ Socio-economic status } \\
\hline Low & 21124 & $9456(44.8 \%)$ \\
\hline Medium & 36134 & $17380(48.1 \%)$ \\
\hline High & 4851 & $1436(48.1 \%)$ \\
\hline Total & 62109 & $28272(45.5 \%)$ \\
\hline
\end{tabular}

\section{Experiment}


The method of data collection, a standardised and validated study-questionnaire based on the International Union Against Tuberculosis and Lung Diseases (IUATLD) respiratory symptom questionnaire was developed. The questionnaire had a special section on tobacco smoking.

All data were analysed centrally at the coordinating centre J.K .Cancer Institute Kanpur .

\section{Discussion}

Adolescents and children are the prime targets of the tobacco industry when recruiting new smokers. About 20 million children of ages 10-14 are estimated to be tobacco addicted according to a survey done by the National Sample Survey Organization of the Indian Government. A number of factors influence the use of tobacco by children and teenagers. Some of these are the family history of tobacco use by elders, peer influence, experimentation, easy access to such products, personality factors, underlying emotional and psychological problems, accompanied risk-taking behaviors,and most importantly, the aggressive marketing strategies of the tobacco industry. Adolescents typically become addicted to nicotine while still being teenagers.Usual interval between the first cigarette consumption and daily smoking is 1-2 year(s). One can see Table $3 \& 4$. A number of epidemiological surveys has been conducted in different parts of India to study the prevalence of tobacco use by adolescents.

Table 3B. role models' ever seen smoking cigarette by students $n=369$

\begin{tabular}{|c|c|c|c|c|c|}
\hline Father & Mother & Brother/Sister & $\begin{array}{c}\text { Best } \\
\text { friend }\end{array}$ & Teacher & $\begin{array}{c}\text { Favourite } \\
\text { celebrity }\end{array}$ \\
\hline 132 & 2 & 23 & 63 & 52 & 142 \\
\hline
\end{tabular}

Table 4. Health Risk Behaviours Concerning Tobacco Use Among Adolescents

\begin{tabular}{|c|c|c|}
\hline Behavour & $\begin{array}{c}\text { males } \\
\mathrm{n}=369\end{array}$ & $\begin{array}{c}\text { females } \\
\mathrm{n}=181\end{array}$ \\
\hline Ever tried cigarette or beedi & 68 & 20 \\
\hline Age at first smoking $\geq 13 \mathrm{y}$ & 27 & 8 \\
\hline $\begin{array}{c}\text { Current cigarette/beedi use } \\
\text { time in 30 days }\end{array}$ & 34 & 5 \\
\hline Current heavy smoking & 6 & 0 \\
\hline
\end{tabular}

A standardised and validated study-questionnaire based on the International Union Against Tuberculosis and Lung Diseases (IUATLD)respiratory symptom questionnaire was developed. This questionnaire was translated to local languages (Hindi ) and minor modifications done depending upon local needs. The method of data collection from the field in each region was uniform. The questionnaire had a special section on tobacco smoking (both active and passive). In case of non-smokers, details of household exposure to ETS during childhood and adulthood were collected. After excluding smokers (defined as people with life time exposure equal to or more than 400 cigarettes or bidis), the prevalence of asthma and respiratory symptoms were studied in relation to ETS exposure.

It has been earlier shown that ETS can cause increased morbidity in adult asthmatics and can precipitate acute attacks . Environmental tobacco smoke has also been shown to be associated with development of bronchial hyper-responsiveness (BHR) in asymptomatic individuals and worsening of BHR in asthmatics Here we describe the effects of ETS exposure on prevalence of asthma and respiratory symptoms in non-smoking adults.

Table 5. Studies On Tobacco Use Among School And College Students

a) EM: English language,

b) PIL: Private Indian language,

c) MIL: Municipal Indian language.

\section{School and college students}

$(\mathrm{N}=1386, \mathrm{M}-81.5 \%, \mathrm{~F}-18.5 \%)$

$5-10$ in $36.1 \% 11-15$ in $44.0 \% 16-20$ in $19.9 \% 12 \%$ in total sample;

$6 \%$ in $13-14$ age group; $15 \%$ in $>18$ age group; $\mathrm{M}=14.2 \% \mathrm{~F}=2.3 \%$

$7.1 \%$ (smoked in the previous week) $29 \%$ (of all smokers)

\section{Smoking in Urban school students}

$(\mathrm{N}=1633, \mathrm{M}-78.4 \%, \mathrm{~F}-21.6 \%)$

EMa schools $-22.5 \%$ in boys

PILb schools $-6.9 \%$ in boys

MILc schools $-13.8 \%$ in boys

Girls $-1.1 \%$-- -- $86 \%$ smokers

College students $(\mathrm{N}=599, \mathrm{M}-64.6 \%, \mathrm{~F}-35.4 \%)$

$10-12$ in $64 \% 15$ or more in $31 \%$ Smoking in $18 \%$ boys;

Snuff use in $38 \%$ boys and $12 \%$ girls.,

Smoking in $8 \%$ boys --

\section{Smoking and snuff tobacco}

School boys $(\mathrm{N}=467) 10-14$ in $80 \% 20 \%$ in $12-20$ age group $-42 \%$ of all smokers Beedis, cigarettes

The study populations included English medium school, Municipal schools and college students, medical students and street children The prevalence of smoking has been found to vary from 6.9 to $22.5 \%$ among the male school and college students.In the observation Table $5 \& 6$. Among the girls, the prevalence is considerably low varying from $0-2.3 \%$. In fact, tobacco use, especially smoking, is a relatively new habit among the Indian female students, noticed only during the last 10-15 years. The prevalence figures vary according to the criteria used to define tobacco use habits.For example, in one study ever smokers constituted $14.2 \%$ of the study population and current smokers (defined as having smoked in the last week) formed $7.1 \%$ of the study sample. More than $40 \%$ of children had started the habit between 10-15 years of age.There was no rural urban difference. Being of male 
gender, having an age above 15 ,smoking by a close relative (father, mother,sister/brother) or friends were significantly associated with smoking by the adolescent children. Both the smokers and nonsmokers were well aware of the adverse health effects of smoking .[6,7,11,12] Considering the enormous adverse health consequences accompanying tobacco addiction, it is very important to develop preventive strategies to reduce tobacco consumption. Preventive strategies especially focused towards children and adolescents need to be initiated on emergent basis. This is more important for the developing countries like India, which have become the main targets of advertisement and promotional propaganda of various multinational tobacco companies .Preventive approaches include spreading awareness about the actual hazards of tobacco in the community especially among the vulnerable children and adolescents, curbs on advertisement and promotional campaigns, early identification of the users and providing treatment.

Table 6. Studies On Tobacco Use Among Medical Students

\begin{tabular}{|l|} 
Male medical students \\
$(\mathrm{N}=400) 15-17--9.2 \%$ tobacco $43 \%$ tobacco; \\
$12.5 \%$ gutka Smoking and tobacco chewing \\
Students of a medical college $(\mathrm{N}=196)$ \\
New admissions to medical colleges \\
$(\mathrm{N}=705, \mathrm{M} 79.0 \%$, F $20.0 \%) 90.1 \%$ in $17-20$ age group-- \\
$17.6 \%$ in males \\
Nil in females -- $3.2 \%$ in males Smoking \\
Students of medical colleges ( $\mathrm{N}=1600)$-- \\
$26.5 \%$; $26.2 \%$ in males \\
$0.25 \%$ in females -- -- Smoking \\
Students of a medical college \\
(N = 672)Age group $17-24$-- Annual prevalence $26.4 \%--9.4 \%$ \\
Smoking
\end{tabular}

\section{REFERENCES}

[1] US Department of Health and Human Services. Public Health Service Office on Smoking and Health. The health consequences of involuntray smoking. A Report of the Surgeon General, Washington, DC: US Government Printing Office, 1986.

[2] US Environmental Protection Agency. Respiratory health effects of passive smoking: lung cancer and other disorders.Washington, DC: Office of Research and Development, 1992,EPA/600/6-90/006F.

[3] Jindal SK, Gupta D. The relationship between tobacco smoke and bronchial asthma. Indian J Med Res 2004; 120:443-53.

[4] Strachan DP, Cook DG. Health effects of passive smoking.6.
Parental smoking and childhood asthma: longitudinal and case-control studies. Thorax 1998; 53: 204-12.

[5] Gupta D, Aggarwal AN, Kumar R, Jindal SK. Prevalence of bronchial asthma and association with environmental tobacco smoke exposure in adolescent school children in Chandigarh, North India. J Asthma 2001; 38: 501-7.

[6] Jindal SK, Gupta D, Singh AJ. Indices of morbidity and control of asthma in patients exposed to environmental tobacco smoke. Chest 1994; 106: 746-9.

[7] Jindal SK, Gupta D, Chattopadhaya S, Kumar L.Environmental tobacco smoke exposure precipitates acute exacerbation in nonsmoker asthmatics. Lung India 1997; 15:168-72.

[8] Jindal SK, Gupta D, D’ Souza GA, Kalra S. Bronchial responsiveness of non-smoking women exposed to environmental tobacco smoke or biomass fuel combustion.Indian J Med Res 1996; 104: 359-64.

[9] Jindal SK, Jha LK. Gupta D. Bronchial hyper-responsiveness of women with asthma exposed to environmental tobacco smoke. Indian J Chest Dis Allied Sci 1999; 41: 75-82.

[10] Aggarwal AN, Chaudhry K, Chhabra SK, D'Souza GA, Gupta $\mathrm{D}$, Jindal SK, et al. Prevalence and risk factors for bronchial asthma in Indian adults: a multicentre study. Indian J Chest Dis Allied Sci 2006; 48: 13-22.

[11] First MW. Costituents of side stream and main stream tobacco and markers to quantify exposure to them. In :Gammag RB, Kaye SV, editors. Indoor Air and Human Health. Chelsea MI: Lewis Publishers. 1985; 195-203.

[12] Spengler JD, Dockery DW, Turner WA, Walfson JM, FerrisBG (Jr). Long term measurements of respirable sulfates and particles inside and outside homes. Atmos Environ 1981; $15: 23-30$.

[13] National Research Council Committee on Passive Smoking.Environmental tobacco smoke: measuring exposures and assesssing health effects. Washington, DC: National Academy Press. 1986.

[14] California Environmental Protection Agency. Health effects of exposure to environmental tobacco smoke. Sacramento,CA: Office of Environmental Health Hazard Assessment; 1997.

[15] Pirkle JL, Flegal KM, Bernert JT, Brody DJ, Etzel RA,Maurer KR. Exposure of the US population to environmental tobacco smoke: The Third National Health and Nutrition Examination Survey, 1988 to 1991. JAMA1996; 275: $1233-40$.

[16] Jindal SK, Gupta D, Aggarwal AN. Environmental tobaccosmoke exposure and asthma. In: Tersa M, editor. Focus onAsthma Research. New York: Nova Publishers. 2004; pp 307-24.

[17] Lee Jong-wook, WHO Director-General's message Tobacco and poverty: a vicious circle (C) Copyright 2004 World Health Organization

[18] Handbook of Environmental Data on Organic Clinical Data Vol 2

[19] Encyclopedia of Clinical Toxicology pp744-45 
[20] UNCTAD's eleventh quadrennial conference held in Sao Paulo, Brazil on 13-18 June 2004. (C) Copyright 2004 World Health Organization

[21] World Health Organization 2004 World No Tobacco Day 2004 - 31 May Globalization of the Tobacco Epidemic Tobacco Control and Development 17 June 2004, $10 \mathrm{~h} 00$ 13h00, Room A C Copyright 2004 World Health

\section{Organization}

[22] Rohit Sharma, tobacco use by adolescents Ind J community medicine 35,2010

[23] Chadda RK, Sengupta SN, Tobacco use by Indian adolescents,Department of Psychiatry, Institute of Human Behavior \& Allied Sciences, Delhi, India 